\title{
Influência do sexo e do sistema de terminação de cordeiros Texel $x$ Corriedale na qualidade da carcaça e da carne
}

\section{Marlice Salete Bonacina ${ }^{1}$, Maria Teresa Moreira Osório², José Carlos da Silveira Osório², Gladis Ferreira Corrêa ${ }^{3}$, Juliano Hideo Hashimoto ${ }^{1}$}

\footnotetext{
1 Pós-Graduando em Zootecnia-FAEM/UFPeL.

2 Departamento de Zootecnia-FAEM/UFPeL.

3 Universidade Federal do Pampa.
}

RESUMO - Neste trabalho o objetivo foi avaliar o efeito do sexo e do sistema de terminação de cordeiros Texel $\times$ Corriedale sobre as características subjetivas da carcaça e as medidas instrumentais e químicas da carne. Foram utilizados 90 animais, 45 deles cordeiros machos não-castrados e 45 fêmeas, mantidos em pastagem com a mãe até o desmame (70 dias); e terminados em três sistemas de produção: apenas pastagem; mantidos na pastagem com a mãe e pastagem com suplementação (casca de soja em nível correspondente a 1\% do peso vivo dos cordeiros). Após o abate dos animais, as carcaças foram armazenadas em câmara fria $\left(1^{\circ} \mathrm{C}, 24\right.$ horas) para medidas de $\mathrm{pH}$, marmoreio, estado de engorduramento, cor e textura. Na sequência, foi retirado o músculo longissimus dorsi da meia-carcaça, para a análise instrumental e química. A análise de variância e o teste de Tukey foram utilizados para comparação da média a 5\% de significância. Não ocorreu interação de sexo e sistema de terminação dos animais nas características avaliadas na carcaça. Igualmente, não ocorreu interação entre sexo e sistema de terminação, porém os fatores isolados tiveram efeito significativo na força de cisalhamento e nos teores de umidade e gordura. A carne dos machos e dos animais terminados mantidos com a mãe apresentam maior resistência à força de cisalhamento e maior umidade, porém menor teor de gordura.

Palavras-chave: composição química, cor, maciez, ovinos, pH

\section{The influence of sex and finishing system on carcass and meat quality of Texel $\times$ Corriedale lambs}

\begin{abstract}
In this work we aimed to evaluate the effect of sex and finishing systems on individual characteristics of carcass, instrumental and chemical meat measurements of Texel $\times$ Corriedalle lambs. Ninety animals were used; 45 noncastrated rams and 45 females. Lambs were kept on pasture with mother to weaning (70 days) and assigned to one of three production systems: pasture, pasture with mother, and on pasture receiving a soy peel supplement at $1 \%$ of live weight basis. After slaughtering, carcasses were stored under vacuum in a freezer at $1{ }^{\circ} \mathrm{C}$ for $\mathrm{pH}$, marbling, fat condition, color and texture measurements. The longissimus dorsi muscle was separated from the half carcass to proceed instrumental and chemical analysis. Analysis of variance and Tukey test were used for comparison of the mean at $5 \%$ significance. There was no interaction for sex and finishing system on carcass characteristics. Similarly, there was no interaction between sex and termination system as related to instrumental measurements and meat chemical composition. Conversely, the isolated factors affected significantly the shearing force, moisture and fat content. Rams meat and the meat of the lambs kept on pasture with mother presented better resistance to shearing force and moisture, but less fat content.
\end{abstract}

Key Words: chemical composition, color, pH, sheep, tenderness

\section{Introdução}

O mercado de carne ovina no Brasil tem expandido de forma significativa nos últimos tempos, sendo que o rebanho brasileiro está concentrado principalmente nas regiões Nordeste, 56\%, e Sul, 32\% (Anualpec 2006).

Junto com o aumento da produção ovina, crescem também as exigências do mercado consumidor, fato que assinala para a necessidade de se conhecerem os fatores que interferem nas características físicas e químicas da carne, pois estas determinam sua qualidade e aceitabilidade (Martínez-Cerezo et al., 2005).

A padronização das carcaças de cordeiros a ser colocadas no mercado também é necessária para valorizar o produto e atrair o consumidor. As carcaças devem apresentar elevada proporção de músculos, cobertura de 
gordura subcutânea uniforme e teor de gordura adequado ao mercado consumidor (Bueno et al., 2000).

A cor da carne é o índice de frescor e qualidade mais óbvio para o consumidor (Sarantopoulos \& Pizzinatto, 1990). Normalmente, carnes escuras são rejeitadas pelo consumidor, que associa a cor escura a carnes com maior vida útil ou oriundas de animais velhos. Entretanto, essa relação nem sempre é verdadeira, pois a carne de animais abatidos com pouca reserva de glicogênio não atinge valores de $\mathrm{pH}$ suficientemente baixos para produzir colorações normais, independentemente de sua idade (Sainz, 1996).

A textura, para os vários tipos de carnes, é o critério de qualidade mais importante. Embora seja ampla a faixa de aceitação de maciez pelos consumidores, é certo que há vantagens para a carne mais macia quando os outros fatores são constantes (Bressan \& Beraquet, 2002).

Segundo Sañudo \& Sierra (1993), a capacidade de retenção de água é um parâmetro biofísicoquímico que pode ser definido como maior ou menor nível de fixação da água de composição do músculo nas cadeias de actina-miosina. É um parâmetro de grande importância econômica e sensorial.

A composição química também influencia a qualidade da carne e varia de acordo com fatores como raça, sexo e alimentação (Sainz, 1996). O teor em proteínas com alto valor biológico é uma característica positiva da carne ovina (Pilar et al., 2002), assim como o de lipídios, que, além de ter elevado valor energético, é composto por ácidos graxos essenciais e influencia nas características sensoriais do produto (Franco, 1999).

Este trabalho foi conduzido com o objetivo de avaliar o efeito do sexo e do sistema de terminação de cordeiros mestiços Texel $\times$ Corriedale nas características subjetivas da carcaça e nas medidas instrumentais e químicas da carne.

\section{Material e Métodos}

O trabalho experimental em sua fase de campo foi realizado entre os meses de outubro de 2006 a maio de 2007, em uma propriedade rural situada no município de Arroio Grande no estado do Rio Grande do Sul, localizada entre os paralelos $32^{\circ} 142163$ sul e $53^{\circ} 052133$ oeste, onde o clima é subtropical, com estações bem definidas e temperatura média anual de $17,5^{\circ} \mathrm{C}$. A fase laboratorial foi desenvolvida no Laboratório de Análise Instrumental e Sensorial e no Laboratório de Nutrição Animal do Departamento de Zootecnia da Faculdade de Agronomia Eliseu Maciel da Universidade Federal de Pelotas.
Foram utilizados 90 animais, 45 cordeiros machos não-castrados e 45 fêmeas. Os animais foram mantidos em pastagem com as mães até o desmame (70 dias) e foram terminados em três sistemas de produção: apenas pastagem; pastagem ao pé da mãe; e pastagem com suplementação (casca de soja em nível correspondente a 1\% do peso vivo). Em cada sistema de produção, foram utilizados 15 fêmeas e 15 machos não-castrados distribuídos aleatoriamente. Todavia, no decorrer do experimento, duas fêmeas do tratamento pastagem com suplementação vieram a óbito, ficando este com 28 animais.

Os cordeiros criados em pastagem com a mãe permaneceram em um piquete com predomínio de gravatá (Eryngium horridum), 31,96\%, quicuio (Pennisetum clandestinum), 22,86\%, carqueja (Baccharis trimera), 18,05\%, e cabelo-de-porco (Piptochaetium montevidense) $6,02 \%$, enquanto, para aqueles terminados apenas em pastagem, a vegetação foi composta predominantemente de grama-seda (Cynodon dactylon), 32,63\%, azevém-anual (Lolium multiflorum), 10,31\%, gravatá (Eryngium horridum) 3,51\%, e aveia-preta (Avena strigosa), 1,96\%. Já os cordeiros terminados em pastagem ou em pastagem com suplementação alimentaram-se de vegetação com predomínio de Pennisetum clandestinum (22,52\%), Eryngium horridum (7,43\%), Lolium multiflorum $(7,24 \%)$ e Cynodon dactylon (5,34\%). A avaliação da pastagem foi realizada pelo método botanal (Tothill et al., 1992).

Os animais foram abatidos conforme as normas da Instrução Normativa do Ministério da Agricultura e Abastecimento - Secretaria de Defesa Agropecuária (Brasil, 2000) adotando-se como critério a condição corporal, que deveria variar na faixa de 2 a 3, seguindo a exigência do mercado consumidor naquele momento. A avaliação da condição corporal foi realizada por palpação ao longo das apófises espinhosas dorsais, lombares e da base da cauda, conforme metodologia descrita por Osório et al. (1998).

Após o abate dos cordeiros, foi medido o $\mathrm{pH}$ no músculo longissumus dorsi, entre a $12^{\text {a }}$ e $13^{\underline{a}}$ costelas, e realizada a leitura do $\mathrm{pH}$, às 0,6 e 24 horas post mortem com auxílio de um peagâmetro digital portátil, marca Marte modelo MB10, segundo Osório et al. (1998). Após 6 horas de abate, as carcaças foram armazenadas em câmara fria, com ar forçado, a temperatura de $1{ }^{\circ} \mathrm{C}$ até completar 24 horas post mortem. Nesta ocasião, realizou-se a avaliação visual do estado de engorduramento das carcaças, quando foram seccionadas ao meio, com auxílio de serra elétrica, de forma simétrica longitudinalmente. Na meia-carcaça esquerda, foi feita uma secção transversal no músculo longissimus dorsi, entre a $12^{\mathrm{a}}$ e $13^{\underline{\mathrm{a}}}$ costelas, para avaliações subjetivas 
de textura, marmoreio e cor da carne em sua superfície, de acordo com descrição de Osório \& Osório (2003).

Na sequência, foi retirado o músculo longissimus dorsi das meias-carcaças, para a análise instrumental, mantendo as amostras a $4{ }^{\circ} \mathrm{C}$ até completar 48 horas post mortem, para determinação da capacidade de retenção de água e cor, enquanto as amostras para avaliação da maciez e composição química foram congeladas a $-18^{\circ} \mathrm{C}$ até o momento da análise.

A capacidade de retenção de água foi determinada pelo método de pressão, descrito por Grau \& Hamm (1953) modificado por Sierra (1973). Utilizou-se uma amostra de $5 \mathrm{~g}$ de carne triturada, que foi colocada entre papéis-filtro circulares. Isolaram-se as partes superior e inferior do papel entre duas placas de Petri e colocou-se em cima um peso de 2,250 kg durante cinco minutos. A amostra de carne resultante foi pesada em balança digital e seu valor expresso em porcentagem de água retida.

A cor da carne foi avaliada por dois métodos: a) físicoquímico (Hornsey, 1956): uma amostra de 5 g de carne triturada foi adicionada sucessivamente de $1 \mathrm{~mL}$ de água destilada, $20 \mathrm{~mL}$ de acetona e $0,5 \mathrm{~mL}$ de ácido clorídrico. A mistura foi agitada, mantida por 24 horas em repouso na ausência de luz e filtrada. No líquido obtido, fez-se a leitura em espectrofotômetro digital Micronal B342 II, com uma longitude de onda de $512 \mathrm{~nm}$, obtendo-se o resultado em mg/L de ferro-hemínico em leitura por transmitância; b) colorimetria: a cor do músculo foi avaliada pelo sistema CIELAB utilizando-se colorímetro Minolta Chroma Meter, CR-300, com fator iluminante D65 e ângulo de observação de $0^{\circ}$, calibrado para padrão branco em ladrilho. O sistema utilizado considera as coordenadas L* (preto/branco), responsável pela luminosidade, a* (verde/vermelho) pelo teor de vermelho, e b*(azul/amarelo) pelo teor de amarelo (Simões \& Ricardo, 2000).

A maciez da carne foi medida através da força de cisalhamento, pelo método de cisalha de Warner-Bratzler Shear Force, conforme metodologia proposta por Osório et al. (1998). Antes de realizar a medida da maciez, a carne foi descongelada sob refrigeração a $4^{\circ} \mathrm{C}$ durante 24 horas, enrolada em papel-alumínio e assada até atingir temperatura interna de $70^{\circ} \mathrm{C}$. Posteriormente, foi cortada paralelamente às fibras musculares, com auxílio de um vazador com $1,2 \mathrm{~cm}^{2}$ de diâmetro. A força de cisalhamento foi registrada pelo aparelho Instron, acoplado a um acessório Warner-Bratzler, medindo a força máxima, expressa em kgf.

Os parâmetros de umidade, proteína, gordura e cinzas foram determinados segundo metodologia indicada por AOAC (2000), na carne previamente descongelada a $4{ }^{\circ} \mathrm{C}$ por 24 horas.
No experimento foi utilizado delineamento inteiramente casualizado, sendo a análise estatística realizada por meio do programa Software Estatística 6.0, no módulo de análise de variância, utilizando o teste Tukey com nível de significância de $5 \%$, seguindo o modelo matemático $\mathrm{Y}_{\operatorname{lmn}}=$ média $+\operatorname{Sexo}_{1}+$ Terminação ${ }_{m}+$ Interação de Sexo/ Terminação ${ }_{l m}+$ erro experimental ${ }_{l m n}$; em que $\mathrm{Y}$ são as características avaliadas.

\section{Resultados e Discussão}

A condição corporal dos cordeiros realizada no préabate não sofreu influência $(\mathrm{P}>0,05)$ da interação sexo $\times$ sistema de terminação dos animais. Não houve também efeito significativo desses fatores isolados (sexo e sistema de terminação), sendo o valor médio obtido 2,4 (coeficiente de variação 16,27\%). Resultado semelhante foi encontrado por Siqueira \& Fernandes (2000) e Osório et al. (2002), que abateram cordeiros mestiços Ile de France $\times$ Corriedale e Border Leicester $\times$ Corriedale, respectivamente, com condição corporal de 2,7. Cartaxo (2006), por sua vez, verificou que o escore corporal de 2,98 foi ideal para abate de cordeiros da raça Santa Inês.

Na avaliação subjetiva das carcaças, também não ocorreu interação sexo $\times$ sistemas de terminação dos cordeiros $(p>0,05)$ nem efeito significativo dos fatores isolados (sexo e sistema de terminação) sobre as características subjetivas avaliadas (Tabela 1).

O valor médio do marmoreio das carcaças dos cordeiros foi de 2,2, superior ao encontrado por Rota et al. (2004), de 1,32 em cordeiros machos não-castrados Texel $\times$ Corriedale criados em campo natural com suplementação concentrada. Motta et al. (2001) obtiveram valor médio de 2,8 para a medida de marmoreio em carcaças de cordeiros da raça Texel. Esses autores verificaram que o método de alimentação não influenciou esta medida, porém houve efeito significativo de sexo, com valores médios de 2,36 e 3,33 para machos e fêmeas, respectivamente.

Em relação ao estado de engorduramento das carcaças, resultado semelhante foi obtido por Bonacina et al. (2007), que estudaram a relação in vivo e da carcaça de cordeiros Corriedale $\times$ Texel e obtiveram valor médio de 2,9 para o

Tabela 1 - Medidas subjetivas realizadas nas carcaças

\begin{tabular}{lcc}
\hline Medidas subjetivas & Valor & Coeficiente de variação \\
\hline Marmoreio & 2,2 & $27,1 \%$ \\
Estado de engorduramento & 2,8 & $17,6 \%$ \\
Cor & 2,9 & $18,1 \%$ \\
Textura & 3,8 & $12,7 \%$
\end{tabular}

$\mathrm{N}=88$ animais. 
estado de engorduramento de carcaça. Os valores encontrados para condição corporal $(2,4)$ e estado de engorduramento $(2,8)$ da carcaça são próximos e corroboram os descritos por Sañudo \& Sierra (1986). Segundo esses autores, o estado de engorduramento das carcaças de cordeiros é um dos principais componentes influenciável pelas variações nas características in vivo do animal, por exemplo, na medida da condição corporal.

Para cor e textura da carne das carcaças, os valores foram similares aos encontrados por Osório et al. (2005), correspondendo à cor vermelho-claro e carne de textura fina. Osório et al. (2002) estudaram o cruzamento de carneiros Border Leicester com ovelhas Ideal e Corriedale e obtiveram valores médios para a cor de 2,8 e 2,7, respectivamente.

$\mathrm{O}$ pH das carcaças, medido no músculo longissimus dorsi, não sofreu influência da interação sexo $\times$ sistema de terminação dos cordeiros $(\mathrm{P}>0,05)$, assim como de nenhum desses fatores isolados (sexo e sistema de terminação). Esses resultados corroboram os obtidos por Hopkins et al. (2001), Mcgeehin et al. (2001) e Diaz et al. (2003), que também não encontraram diferença significativa ao compararem o pH final da carcaça de fêmeas e machos, e Zeola et al. (2002), que observaram que diferentes níveis de concentrado não influenciaram o $\mathrm{pH}$ final da carcaça de cordeiros Morada Nova.

O declínio do $\mathrm{pH}$ apresentou rápida queda nas primeiras horas post mortem, com valores médios de 6,7 (pH 0 horas), 6,06 (pH 6 horas) e 5,4 (24 horas post mortem) (Figura 1). Essa curva comprova que houve maior velocidade de declínio do $\mathrm{pH}$ nos primeiros horários e tendência à estabilização a partir de 12 horas. A queda de $\mathrm{pH}$ é resultado da utilização das reservas de glicogênio via glicólise, que tem como produto final o ácido lático.

Rota et al. (2004) encontraram valor similar para $\mathrm{pH}$ inicial em carcaça de cordeiros Texel $\times$ Corriedale, enquanto o valor médio do $\mathrm{pH} 6$ horas post mortem encontra-se na faixa dos valores obtidos por Bressan et al. (2001), que variaram de 5,8 a 6,1 para cordeiros da raça Santa Inês e Bergamácia com diferentes pesos de abate. No entanto, o valor médio de $\mathrm{pH}$ final (24 horas post mortem) encontrado situa-se no limite inferior da faixa de variação dos valores apresentados na literatura, pois, conforme Young et al. (2004) o pH final considerado normal varia na faixa de 5,4-5,6.

É importante ressaltar que a constatação de valores normais de queda do $\mathrm{pH}$ da carcaça sugere que outros parâmetros indicadores da qualidade, como capacidade de retenção de água, sabor, cor e textura apresentarão bons resultados, pois, durante o desenvolvimento do rigor mortis, o pH tem influência marcante na contração, proteólise e desnaturação proteica, acarretando mudanças na sua estrutura e qualidade (Ramos \& Gomide, 2007).

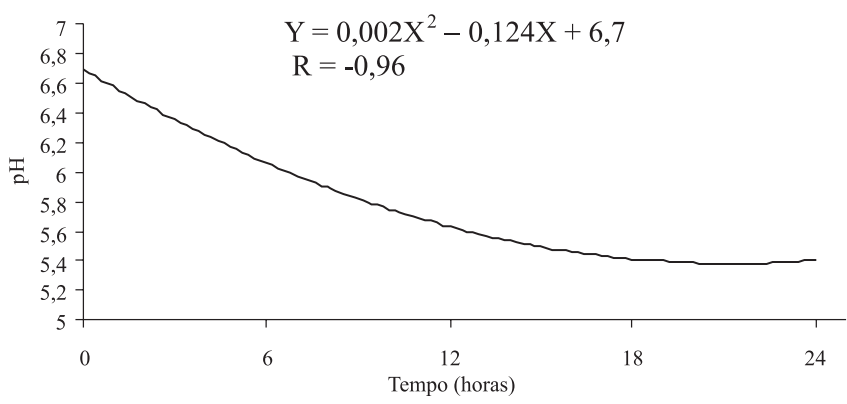

Figura 1- Declínio do pH nas carcaças dos cordeiros.

Na avaliação instrumental da carne, não houve interação ( $p>0,05)$ entre sexo e sistema de terminação dos cordeiros. No entanto, os fatores isolados tiveram efeito significativo $(\mathrm{p}<0,05)$ apenas para a força de cisalhamento quando comparado o sexo e os sistemas de terminação dos cordeiros (Tabela 2).

Na carne das fêmeas, foi necessária menor força de cisalhamento e isso indica que é necessária menor força para rompimento das fibras da carne, que, portanto, é mais macia que a dos machos não-castrados. Na comparação dos sistemas de terminação, a carne dos cordeiros terminados em pastagem ao pé da mãe foi a que apresentou maior resistência à força de cisalhamento $(2,84)$, fato que pode ser atribuído ao maior deslocamento desses cordeiros com as mães, já que estas necessitavam caminhar mais em busca de maior quantidade de pasto. A maior quantidade de mioglobina corrobora esse resultado, pois o valor de "a" foi maior na carne desses cordeiros, mesmo não apresentando diferença significativa em relação aos demais. Vestergaard et al. (2000) também observaram que a carne de animais produzidos em sistema extensivo apresenta coloração mais escura, em virtude da maior concentração de mioglobina, necessária para promover melhor oxigenação do músculo, pois há maior atividade física desenvolvida pelos animais a pasto.

Resultados similares para força de cisalhamento foram descritos por Clare et al. (1997), com variação de 2,8 a 3,0 kgf, ao passo que Rota et al. (2004) encontraram valor médio de 2,03 para a força de cisalhamento de cordeiros mestiços Texel $\times$ Corriedale, ao estudarem o efeito do cruzamento sobre a qualidade da carne. Cañeque et al. (2004) registraram valores médios de 1,76 e 2,39 kgf para força de cisalhamento em carne de cordeiro cozida e crua, respectivamente.

No entanto, valores maiores foram relatados por Monteiro et al. (2001), Zeola et al. (2002) e Silva Sobrinho et al. (2005), cuja variação foi de 3,35 a 6,27 kgf. Essas divergências nos valores de força de cisalhamento ocorrem por inúmeros motivos, por exemplo: manejo empregado no pré-abate, velocidade na instalação do rigor mortis, $\mathrm{pH}$ 
Tabela 2 - Valores de capacidade de retenção de água (CRA), força de cisalhamento (FC) e cor da carne, para sistemas de terminação e sexo

\begin{tabular}{|c|c|c|c|c|c|c|c|}
\hline \multirow{2}{*}{$\begin{array}{c}\text { Medidas } \\
\text { Instrumentais }\end{array}$} & \multicolumn{4}{|c|}{ Sistema de terminação } & \multicolumn{2}{|c|}{ Sexo } & \multirow[t]{2}{*}{ CV (\%) } \\
\hline & Pastagem & Pastagem ao pé da mãe & Pastagem & com suplementação & Fêmea & Macho & \\
\hline CRA (\%) & $77,86 a$ & $78,95 a$ & & $80,33 a$ & $79,43 \mathrm{~A}$ & $79,05 \mathrm{~A}$ & 4,00 \\
\hline FC (Kgf) & $2,33 b$ & $2,84 \mathrm{a}$ & & $2,55 b$ & $2,33 \mathrm{~B}$ & $2,59 \mathrm{~A}$ & 11,78 \\
\hline $\mathrm{L}^{*}$ & $47,87 \mathrm{a}$ & $49,49 a$ & & $49,02 \mathrm{a}$ & $51,70 \mathrm{~A}$ & $49,86 \mathrm{~A}$ & 20,08 \\
\hline$a^{*}$ & $18,74 \mathrm{a}$ & $20,52 a$ & & $18,87 a$ & $18,18 \mathrm{~A}$ & $18,48 \mathrm{~A}$ & 16,58 \\
\hline$b^{*}$ & $9,05 a$ & $10,54 a$ & & $10,81 \mathrm{a}$ & $10,23 \mathrm{~A}$ & $11,06 \mathrm{~A}$ & 28,06 \\
\hline $\operatorname{Cor}^{1}$ & $54,40 \mathrm{a}$ & $57,17 \mathrm{a}$ & & $54,83 a$ & $53,26 \mathrm{~A}$ & $55,00 \mathrm{~A}$ & 19,39 \\
\hline
\end{tabular}

$\mathrm{CV}=$ coeficiente de variação; $\mathrm{L}^{*}=$ luminosidade; $\mathrm{a}^{*}=$ Vermelho; $\mathrm{b}^{*}=$ amarelo.

1 mg/L de ferro-hemínico em leitura por transmitância.

Médias seguidas de letras minúsculas diferentes na mesma linha diferem $\mathrm{p}<0,05$ para terminações.

Médias seguidas de letras maiúsculas diferentes na mesma linha diferem $\mathrm{p}<0,05$ para sexo.

no post mortem, temperatura pré-abate, instalação e extensão da glicólise, músculo utilizado, manejo pósabate, condições de acondicionamento e metodologia para as determinações, como temperatura e tempo durante o processo de cocção.

Segundo Bressan (1998), a textura para os vários tipos de carne é o critério de qualidade mais importante. Embora seja ampla a faixa de aceitação de maciez pelos consumidores, é certo que há vantagens para a carne mais macia quando os outros fatores são constantes.

Os valores relativos à cor, determinada pelo método do ferro hemínico, estão de acordo com os índices de a* obtidos pelo sistema CIELAB. A composição da cor $\mathrm{L}^{*}$, $a^{*}, b^{*}$ confirma os resultados obtidos por Dransfield et al. (1990), Hopkins \& Fogarty (1998), Velasco et al. (2000) e Teixeira et al. (2005), que também não encontraram diferenças significativas nos índices de cor no músculo longissimus dorsi entre machos e fêmeas.

Em relação ao sistema de terminação, os animais terminados em pastagem apresentaram menor índice de luminosidade, da cor vermelha e amarela, porém os valores não diferiram dos índices determinados na carne dos demais (Tabela 2). Esses resultados corroboram os obtidos por Zeola et al. (2002), que não notaram diferença significativa nos índices da cor da carne de cordeiros da raça Morada Nova ao avaliarem a influência dos níveis de concentrado na alimentação dos animais. Russo et al. (1999) estudaram o efeito de fontes energéticas na alimentação de cordeiros e também não encontraram efeito das dietas $(\mathrm{p}>0,05)$ sobre a cor da carne ( $\mathrm{L}^{*}, \mathrm{a}^{*} \mathrm{e} \mathrm{b}^{*}$ ) determinada no músculo longissimus dorsi. Da mesma forma, Alberti et al. (1991), citados por Sañudo (1992), não verificaram diferenças $(p>0,05)$ na cor da carne de animais terminados em sistema com suplementação concentrada em relação àqueles mantidos somente em pastoreio.

A capacidade de retenção de água apresentou resultados semelhantes aos obtidos por Osório et al. (2002) e Rota et al. (2004). Os valores encontrados indicam que a carne não apresenta problemas exudativos e está dentro de uma amplitude considerada normal para carne ovina (Perez et al., 2002). A capacidade de retenção de água é indiscutivelmente um fator de qualidade porque afeta a carne antes e durante seu cozimento e influencia na suculência durante a mastigação (Lawrie, 2005; Prändal et al., 1994; Osório \& Osório, 1999).

Na composição química da carne, não houve interação $(p>0,05)$ entre sexo e sistema de terminação dos cordeiros. No entanto, isoladamente, os fatores tiveram efeito $(\mathrm{p}<0,05)$ no teor de umidade e gordura quando comparados os sexos e os sistemas de terminação dos cordeiros.

Os valores de proteína variaram de 18,19 a 18,62\% e o de cinzas, de 0,96 a 0,98\%, independentemente do sexo e do sistema de terminação (Tabela 3). Esses valores estão de acordo com as citações de Pérez et al. (2002), que observaram valores de 18,1 a 18,4\% de proteína na carne de cordeiros Suffolk, enquanto Morris et al. (1995) e Solomon et al. (1980) registraram valores de 0,77 a $1,16 \%$ para cinzas em carne ovina. No entanto, Monteiro et al. (2001), em pesquisa com cordeiros Texel $\times$ Corriedale criados em regime de pasto, encontraram 22\% de proteína no músculo longissimus dorsi, enquanto Klein Junior et al. (2006) registraram valores de 20,38 a 20,72\% de proteína na carne de cordeiros mestiços com predominância da raça Ideal.

As composições em umidade e gordura apresentam comportamento inversamente proporcional, corroborando a afirmação de Pardi et al. (1996) e Osório (1996). Este comportamento pode ser observado nos resultados (Tabela 3), pois as carnes das fêmeas e dos cordeiros terminados em pastagem apresentaram maior teor de gordura e menor umidade, diferindo significativamente $(p<0,05)$ dos demais sistemas de terminação.

Esses resultados de umidade (75,62 a 77,36\%) estão dentro do intervalo descrito por outros autores em pesquisas com carne de cordeiros, entre eles, Klein Junior et al. (2006), 
Tabela 3 - Composição química da carne de cordeiros em três sistemas de terminação

\begin{tabular}{|c|c|c|c|c|c|c|}
\hline \multirow{2}{*}{$\begin{array}{l}\text { Composição } \\
\text { química }\end{array}$} & \multicolumn{3}{|c|}{ Sistema de terminação } & \multicolumn{2}{|c|}{ Sexo } & \multirow[t]{2}{*}{ CV (\%) } \\
\hline & Pastagem & Pastagem ao pé da mãe & Pastagem com suplementação & Fêmea & Macho & \\
\hline Umidade & $75,62 b$ & $77,36 a$ & $76,12 \mathrm{ab}$ & $75,86 \mathrm{~B}$ & $76,96 \mathrm{~A}$ & 3,27 \\
\hline Gordura & $3,95 a$ & $2,86 b$ & $3,60 \mathrm{ab}$ & $4,01 \mathrm{~A}$ & $2,93 \mathrm{~B}$ & 45,85 \\
\hline Cinza & $0,98 a$ & $0,98 a$ & $0,96 \mathrm{a}$ & $0,98 \mathrm{~A}$ & $0,97 \mathrm{~A}$ & 10,20 \\
\hline
\end{tabular}

$\mathrm{CV}=$ coeficiente de variação.

Médias seguidas de letras minúsculas diferentes na mesma linha diferem $\mathrm{p}<0,05$ para terminações.

Médias seguidas de letras maiúsculas diferentes na mesma linha diferem $\mathrm{p}<0,05$ para sexo.

Ortiz et al. (2005), Wiegand (2007). A porcentagem de gordura, no entanto, apresentou diferença significativa $(\mathrm{p}<0,05)$ entre os sexos, corroborando resultados obtidos por Velasco et al. (2000) e Solomon et al. (1992), que encontraram diferenças significativas nos teores de lipídeos entre machos e fêmeas abatidos aos $35 \mathrm{~kg}$ de peso vivo. Segundo Lawrie (2005), em geral, animais machos depositam menos gordura intramuscular, enquanto Reece (1991) afirmou que as fêmeas, na maioria das espécies, apresentam aptidão para acumular mais lipídeos que os machos e essa aptidão começa com as transformações que ocorrem na puberdade.

O teor de gordura da carne dos cordeiros terminados em pastagem ao pé da mãe foi inferior, e diferiu significativamente, quando comparado aos demais tratamentos. Esses resultados comprovam que o provável maior deslocamento desses cordeiros com as mães resulta em maior gasto de energia e, portanto, menor acúmulo de gordura. Essa hipótese pode ser confirmada pelos teores de gordura da carne dos cordeiros terminados em pastagem ao pé da mãe (2,86\%) em comparação ao conteúdo de gordura da carne dos cordeiros criados apenas em pastagem (3,95\%).

Segundo Cañeque et al. (1989), citados por Zeola et al. (2004), a proporção e as características da gordura na carne são influenciadas pela alimentação, pois alimentação rica em concentrados resulta em carne com maior teor de gordura, fato que não foi verificado neste estudo, uma vez que não houve diferença significativa no teor de gordura quando comparada a carne dos cordeiros alimentados apenas com pastagem à daqueles que receberam a suplementação (Tabela 3).

De acordo com Sañudo (2002), a deposição de gordura intramuscular está associada à maciez da carne. Ramsey \& Tribble (1987), Hoffman et al. (2003) e Schonfeldt et al. (1993) relataram associação positiva entre a gordura muscular e a maciez, fato verificado neste trabalho, pois os machos e os cordeiros terminados em pastagem ao pé da mãe apresentaram menor teor de gordura na carne (Tabela 3) e maior força de cisalhamento (Tabela 2), ou seja, menor maciez.

\section{Conclusões}

O sistema de terminação e o sexo dos cordeiros Texel $\times$ Corriedale não influenciam as características subjetivas da carcaça, porém afetam a maciez e os teores de umidade e gordura da carne.

\section{Referências}

ANUAlPEC 2006. Anuário da Pecuária Brasileira. São Paulo: Instituto FNP, 2006.

ASSOCIATION OF OFFICIAL ANALYTICAL CHEMISTIS AOAC. Official methods of analysis. 13.ed. Arlington: AOAC International, 2000. 989p.

BONACINA, M.; OSÓRIO, J.C.S.; OSÓRIO, M.T.M. et al. Otimização da avaliação in vivo e da carcaça em cordeiros Revista da Faculdade de Zootecnia, Veterinária e Agronomia, v.14, n.1, p.273-286. 2007.

BRASIL. Ministério da Agricultura, Pecuária e Abastecimento. Instrução Normativa $\mathrm{n}^{\circ}$. 3, de 17 de janeiro de 2000. Regulamento técnico de métodos de insensibilização para o abate humanitário de animais de açougue. S.D.A./M.A.A. Diário Oficial da União, Brasília, p.14-16, 24 de janeiro de 2000, Seção I.

BRESSAN, M.C.; BERAQUET, N.J. Efeito dos fatores pré e pós abate sobre a qualidade da carne de peito de frango. Ciência e Agrotecnologia, v.26, n.5, p.1049-1059, 2002.

BRESSAN, M.C.; PRADO, O.V.; PÉREZ, J.R. et al. Efeito do peso ao abate de cordeiros Santa Inês e Bergamácia sobre as características físico-químicas da carne. Ciência e Tecnologia de Alimentos, v.31, n.3, p.293-303, 2001.

BUENO, S.M.; CUNHA, L.E.; SANTOS, L.E. et al. Características de carcaças de cordeiros Sffolk abatidos em diferentes idades. Revista Brasileira de Zootecnia, v.29, n.6, p.1803-1810, 2000.

CAÑEQUE, V.; PEREZ, C.; VELASCO, A. et al. Carcass and meat quality of light lambs using principal component analysis. Meat Science, v.67, p.595-605, 2004

CARTAXO, F.Q. Efeito do genótipo e da condição corporal sobre o desempenho, predição e avaliação de carcaça de cordeiros terminados em confinamento. 2006. $138 \mathrm{f}$. Dissertação (Mestrado em Zootecnia) - Universidade Federal da Paraíba.

CLARE, T.L.; JACKSON, S.P.; MILLER, M.F. et al. Improving tenderness of normal and callipyge lambs with calcium chloride. Journal of Animal Science, v.75, p.377-385, 1997.

DÍAZ, M.T.; VELASCO, S.C.; PÉREZ, S. et al. Physico-chemical characterististics of carcass and meat Manchego-breed suckling lambs slaughtered at different weights. Meat Science, v.65, p.1247-1255, 2003.

DRANSFIELD, E.; NUTE, G.R.; HOGG, B.W. et al. Carcass and eating quality of ram, castrated ram and ewe lambs. Animal Production, v.50, p.291-299, 1990. 
FRANCO G. Tabela de composição química dos alimentos. 9.ed. São Paulo: Atheneu, 1999. 307p.

HOFFMAN, L.C.; MULLER, M.; CLOETE, S.W.P. Comparasiona of six crossbred lamb types: sensory, physical and nutritional meat quality characteristics. Meat Science, v.65, p.1265-1274, 2003.

HOPKINS, D.L.; FOGARTY, N.M. Diverse lamb genotypes. 2. Meat $\mathrm{pH}$, colour and tenderness. Meat Science, v.49, p.477-488, 1998.

HOPKINS, D.L.; HALL, D.G.; CHANNON, H.A. Meat quality of mixed sex lambs grazing pasture and supplemented with, roughage, oats or oats and sunflower meat. Meat Science, v.59, p.277-283, 2001.

HORNSEY, H.C. The color of cooked cured pork. I. Estimation of the nitric oxide-haem pigments Journal Science Food Agriculture, n.7, p.534-540, 1956.

KLEIN JÚNIOR, M.H.; SIQUEIRA, E.R.; ROÇA, R.O. Qualidade da carne de cordeiros castrados e não-castrados confinados sob dois fotoperíodos. Revista Brasileira de Zootecnia, v.35, n.4, p.1872-1879, 2006.

LAWRIE, R.A. Ciência da carne. 6.ed. Editora Artmed, 2005. $384 \mathrm{p}$.

MARTÍNEZ-CEREZO, S.; SAÑUDO, C.; PANEA, B. et al. Breed, slaughter weight and ageing time effects on consumer appraisal of three muscles of lamb. Meat Science, v.69, p.795-805, 2005.

MCGEEHIN, B.; SHERIDAN, J.J.; BUTTER, F. Factors affecting the $\mathrm{pH}$ declive in lamb after slaughter. Meat Science, v.58, p.79-84, 2001

MONTEIRO, E.M. RÜBENSAN, J.; PIRES, G. Avaliação de parâmentros de qualidade da carcaça e da carne de ovinos. In : CONGRESSO BRASILEIRO DE TECNOLOGIA DE CARNES, 1. 2001, São Pedro. Anais... São Pedro: CTC-ITAO, 2001. p.99.

MONTEIRO, E.M.; SHIMOKOMAKI, M.; GIOELLI, L.A. Influência do cruzamento na maciez da carne ovina. In: CONGRESSO BRASILEIRO DE VETERINÁRIA (CONBRAVET), 28., 2001, Salvador. Anais... Salvador: CONBRAVET, 2001. (CD-ROM).

MORRIS, C.A.; KIRTON, A.H.; HOGG, B.W. et al. Meat composition in genetically selected and control cattle from a serial slaughter experiment. Meat Science, v.39, n.3, p.427-435, 1995.

MOTTA, O.S.; PIRES, C.C.; SILVA, J.H.S. et al. Avaliação da carcaça de cordeiros da raça Texel sob diferentes métodos de alimentação e pesos de abate. Ciência Rural, v.31, n.6, p.1051-1056, 2001.

ORTIZ, J.S.; COSTA, C.; GARCIA, C.A. et al. Medidas objetivas das carcaças e composição química do lombo de cordeiros alimentados e terminados com três níveis de proteína bruta em creep feeding. Revista Brasileira de Zootecnia, v.34, n.6, p.2382-2389, 2005

OSÓRIO, J.C.S.; OSÓRIO, M.T.M.; JARDIM, P.O.C. et al. Métodos para avaliação da produção de carne ovina: "in vivo" na carcaça e na carne. Pelotas: Universidade Federal de Pelotas, 1998. $107 p$.

OSÓRIO, J.C.S.; OSÓRIO, M.T.M. Fatores que afetam a capacidade de retenção de água na carne. In: CURSO DE QUALIDADE DE CARNE E PRODUTOS CÁRNEOS. Bagé: Embrapa - Pecuária Sul, 1999. 65p.

OSÓRIO, J.C.; OLIVEIRA, N.M.; OSÓRIO, M.T.M. et al. Produção de carne em cordeiros cruza Border Leicester com ovelhas Corriedale e Ideal. Revista Brasileira de Zootecnia, v.31, n.3, p.1469-1480, 2002.

OSÓRIO, J.C.; OSORIO, M.T. Produção de carne ovina: in vivo e na carcaça. Pelotas: Universidade Federal de Pelotas; Editora Universitária, 2003. 73p.

OSÓRIO, J.C.S.; OSÓRIO, M.T.M.; MENDONÇA, G. et al. Morfologia e características produtivas e comerciais em cordeiros corriedale castrados e não castrados. Revista Brasileira Agrociência, v.11, n.2, p.211-214, 2005.

OSÓRIO, M.T.M. Estudio comparativo de la calidad de la canal y de la carne em las Razas Aragonesa, Ojinegra de Teruel y Royabilbilitana. 1996. 299f. Tesis (Doutoral - Faculdade de Veterinária) - Universidade Zaragoza, Espanha, 1996.

PARDI,M.C.; SANTOS, I.F.; SOUZA, E.R. et al. Ciência, higiene e tecnologia da carne. Goiânia: Editora da UFG, 1996. 586p.

PEREZ, J.R.O.; MAINO, M.; TOMIC, G. Carcass characteristics and meat quality of Suffolk Down sucling lambs. Small Ruminant Research, v.44, p.233-240, 2002.

PILAR, R.C.; PÉREZ, J.R.O.; SANTOS, C.L. et al. Considerações sobre produção de cordeiros. Boletim Agropecuário, n.53, p.1-24, 2002.

PRÄNDAL, O.; FISCHER, A.; SCHMIDHOFER, T. et al. Tecnologia e higiene de la carne. Traduação de ESCOBAR, J.E. Zaragoza: Acribia, 1994. 854p. Tradução de: Fleisch. Technologie und Hygiene der Gewinnung und Verarbeiyung. 1994.

RAMOS, E.M.; GOMIDE, L.A.M. Avaliação da qualidade de carnes: fundamentos e metodologias. Viçosa, MG: Editora UFV, 2007. 599p.

RAMSEY, C.B.; TRIBBLE, L.F. Effect of marbling and dietary grain source on pork muscle tenderness and composition. Journal of Animal Science, v.65, p.284, 1987.

REECE, W.O. Physiology of domestics animals. [S.I.]: Lea and Febiger Ltda, 1991. 351p.

ROTA, E.L.; OSÓRIO, M.T.M.; OSÓRIO, J.C.S. et al. Efeitos do cruzamento de carneiros da raça texel com ovelhas corriedale $e$ ideal sobre a qualidade da carne. Revista Brasileira Agrociência, v.10, n.4, p.487-491, 2004.

RUSSO, C.; PREZIUSO, G.; CASAROSA, L. et al. Effect of diet energy source on the chemical - physi-cal characteristics of meat and depot fat of lambs carcasses. Small Ruminant Research, v.33, n.1, p.77-85, 1999.

SAINZ, R.D. Qualidade das carcaças e da carne ovina e caprina. In: REUNIÃO ANUAL DA SOCIEDADE BRASILEIRA DE ZOOTECNIA, 1996, Fortaleza. Anais... Fortaleza: Sociedade Brasileira de Zootecnia, 1996. p.3-19.

SAÑUDO, C.; SIERRA, I. Calidad de la canal en la especie ovina. Barcelona, España: One, 1986. p.127-153.

SAÑUDO, C. La qualidade organoléptica de la carne com especial referencia a la especie ovina. Factores que la determinan, metodos de medidas y causas de variacion. 1992. 117f. Faculdad de Veterinaria - Departamento Producción Animal y Ciencia de los Alimentos, Zaragoza.

SAÑUDO, C.; SIERRA, I. Calidad de la canal y de la carne en la especie ovina. Ovino y caprino. Madrid: Monografia del Consejo General de Colegios Veterinarios, 1993. p.207-254.

SAÑUDO, C. Factors affecting carcass and meat quality in lambs. In: REUNIÃO ANUAL DA SOCIEDADE BRASILEIRA DE ZOOTECNIA, 2002, Recife. Anais... Recife: Sociedade Brasileira de Zootecnia, 2002. p.434-455.

SARANTOPOULOS, C.I.G.L.; PIZZINATTO, A. Fatores que afetam a cor das carnes. Coletânea ITAL, v.20, n.1, p.1-12, 1990.

SCHONFELDT, H.C.; NAUDE, R.T.; BOK, W. Cooking-and juiciness-related quality characteristics of goat sheep meat. Meat Science, v.34, p.381-394, 1993.

SIERRA, I. Produccion de cordero joven y pesado en la raza. Raza Aragonesa I.P.G.E., n.18, 28p, 1973.

SILVA SOBRINHO, A.G.; SILVA, A.M.A; GONZAGA NETO, S. et al. Parâmetros qualitativos da carcaça e da carne de cordeiros submetidos a dois sistemas de formulação de ração. Agopecuária Científica no Semi-Árido, v.1, p.31-38, 2005.

SIMÕES, J.A.; RICARDO, R. Avaliação da cor da carne tomando como referência o músculo rectus abdominis, em carcaças de borregos leves. Revista Portuguesa de Ciências Veterinárias, v.95, n.535, p.124-127, 2000.

SIQUEIRA, S.L.; FERNANDES, S. Efeito do genótipo sobre as medidas objetivas e subjetivas da carcaça de cordeiros terminados em confinamento. Revista Brasileira de Zootecnia, v.29, n.1, p.306-311, 2000.

SOLOMON, M.B.; KEMP, J.D.; MOODY, W.G. et al. Effect of breed and slaughter weight on physical, chemical and 
organoleptic properties of lamb carcasses. Journal of Animal Science, v.51, n.5, p.1102-1107, 1980.

SOLOMON, M.B.; LINCH, G.P.; LOUGH, D.S. Influence of dietary palm oil supplementation on serum lipid metabolites, carcass characteristics and lipid 8 composition of carcass tissues of growing ram and ewe lambs. Journal of Animal Science, v.70, p.2746-2751, 1992.

STATSOFT, Inc. Statistica (data analysis software system), version 6.0., 2001. Disponível em: <www.statsoft.com>. Acesso em: 5/5/2009.

TEIXEIRA, A.; BATISTA, S.; DELFA, A.R. et al. Lamb meat quality of two breeds with protected origin designation. Influence of breed, sex and live weight Meat Science, v.71, p.530-536, 2005.

TOTHILL, J.C.; HARGREAVES, J.N.G.; JONES, R.N. et al. Botanal - A comprehensive sampling and computing procedure for estimating pasture yield and composition. 1. Field sampling. Tropical Agronomy Technical Memorandum, n.7, 24p, 1992.

VELASCO, S.; LAUZURICA, S.; CAÑEQUE, V. et al. Carcass and meat quality of talaverana breed sucking lambs in relation to gender and slaughter weigth. Animal Science, n.70, p.253-263, 2000 .
VESTERGAARD, M.; OKSBJERG, N.; HENCKEL, P. Influence of feeding intensity, grazing and finishing feeding on muscle fibre characteristics and meat colour of semitendinosus, longissimus dorsi and supraspinatus muscle of youngbulls. Meat Science, v.54, p.177-185, 2000.

WIEGAND, M. Qualidade da carne em cordeiros Texel nascidos em duas épocas e relação entre avaliação in vivo e na carcaça. 2007. 115f. Tese (Doutorado em Ciência) Departamento Zootecnia - Universidade Federal de Pelotas, Pelotas.

YOUNG, O.A.; WETB, J.; HARTC, A.L.A. method for early determination of meat ultimate $\mathrm{pH}$. Meat Science, v.66, p.493-498, 2004.

ZEOLA, N.M.B.L.; SILVA SOBRINHO, A.G.; GONZAGA NETO, S. et al. Influência de diferentes níveis de concentrado sobre a qualidade da carne de cordeiros Morada Nova. Revista Portuguesa de Ciências Veterinárias, v.97, n.544, p.175-180, 2002.

ZEOLA, N.M.B.; SILVA SOBRINHO, A.G.; GONZAGA NETO, S. et al. Composição centesimal da carne de cordeiros submetidos a dieta com diferentes teores de concentrado. Ciência Rural, v.34, n.1, p.253-257, 2004 